\title{
Elongation Factor 1
}

National Cancer Institute

\section{Source}

National Cancer Institute. Elongation Factor 1. NCI Thesaurus. Code C38958.

Heterotrimeric Elong ation Factor 1 (containing alpha/beta/gamma or alpha/delta/gamma subunits) is responsible for delivery of aminoacyl tRNAs to the ribosome. Containing domains that bind guanine nucleotides, 805 ribosomes, and aminoacyl-tRNAs, the alpha EF-1 subunit interacts with beta/delta subunits and mediates delivery and GT P-dependent binding of aminoacyl-tRNAs to the $80 \mathrm{~S}$ ribosome A-site. Homologous beta and delta subunits (guanine nucleotide exchange factors) stimulate GDP/GT P exchange bound to EF-1-alpha; phosphorylation affects the GDP/GTP exchange rate. The conserved gamma subunit contains an EEF1G domain and an Nterminal GST domain that may be involved in regulating EF-1 multisubunit assembly and anchorage to other cellular components. $(\mathrm{NCl})$ 